\title{
Increase robustness of the method of diagnostics and identification of high-precision positioning systems
}

\author{
Anton Lankin ${ }^{1, *}$, Valery Grechikhin ${ }^{1}$, Michail Lankin ${ }^{1}$ \\ ${ }^{1}$ SRSPU (NPI), Department of Information and Measuring Systems and Technologies, 346428 Novocherkassk, Russia
}

\begin{abstract}
Today, high-precision positioning systems are used in various fields of science and technology, providing fast and accurate control of movements. Considering the fact that such systems perform important tasks, diagnostics and timely detection of defects is an urgent task. To effectively diagnose and identify defects of such systems, a method based on the transition to the space of principal components was developed. Such a method will make it possible to represent each characteristic in the form of a point in a new orthogonal space. Despite the possibility of using such a method, a drawback was revealed, which is the low stability of this method to the gross errors in the measurement. In this paper, we propose an approach that provides a significant increase in the stability of the method for diagnosing and identifying high-precision positioning systems.
\end{abstract}

\section{Introduction}

For diagnostics and identification of high-precision positioning systems in $[1,2,3]$ method of principal components (PC) is used, one of the disadvantages of which is the sensitivity to gross errors in measurement (misses). The presence of several such errors greatly distorts the results of the diagnostic, or even completely makes them unreliable. Authors [4], the methods of increasing the robustness of the PC method were investigated [12].

As a high-precision positioning system, proportional electromagnets were considered. To analyze the quality of proportional electromagnets in $[5,6]$ it is proposed to use the dynamic magnetization characteristic (DCM). In this regard, in our opinion, it will be effective to increase the robustness of the diagnostic method by using an approximated polynomial of the sixth degree [7, 13].

\section{Experimental studies of increasing robustness}

An experiment was performed to illustrate this approach. A group of thirty-five DCM was formed [8, 9, 10, 11]. The first (DCM1) is obtained by measuring the proportional electromagnet. The following five characteristics (DCM2- DCM6) were obtained as a result of the addition to the DCM1 points of the random error of current measurement of 1, 2, 3, 4 and 5\%. Four characteristics (DCM7- DCM10) received additions to the coordinates of one point DCM1 gross error in 5\%, $10 \%, 15 \%$ and $20 \%$. The following eight characteristics (DCM11- DCM18) are obtained similarly to the previous four, but adding the same errors at three and five points. The characteristics DCM19- DCM35 is the result of approximation by a sixth-degree polynomial, characteristics beginning with DCM2 according to DCM18.

For clarity, we will represent the DCM1 forms without the introduced error (Figure 1), DCM6 with an error of 5\% (Figure 2) and DCM10 with one point of rough error of $20 \%$ (Figure 3 ). And also their shape after the approximation: DCM23 (Figure 4) and DCM27 (Figure 5).

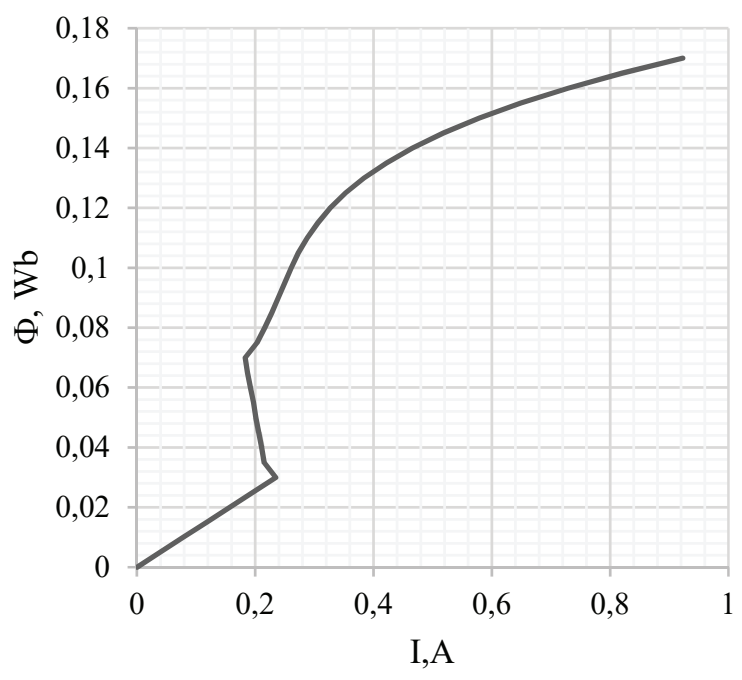

Fig. 1. DCM1 without the introduced error

\footnotetext{
* Corresponding author: lankinjohn@yandex.ru
} 


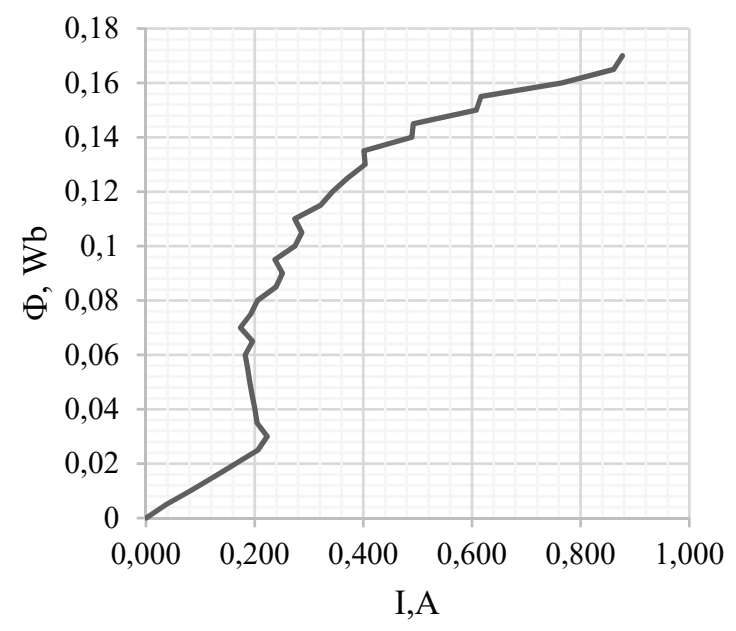

Fig. 2. DCM6 with a random error of 5\%

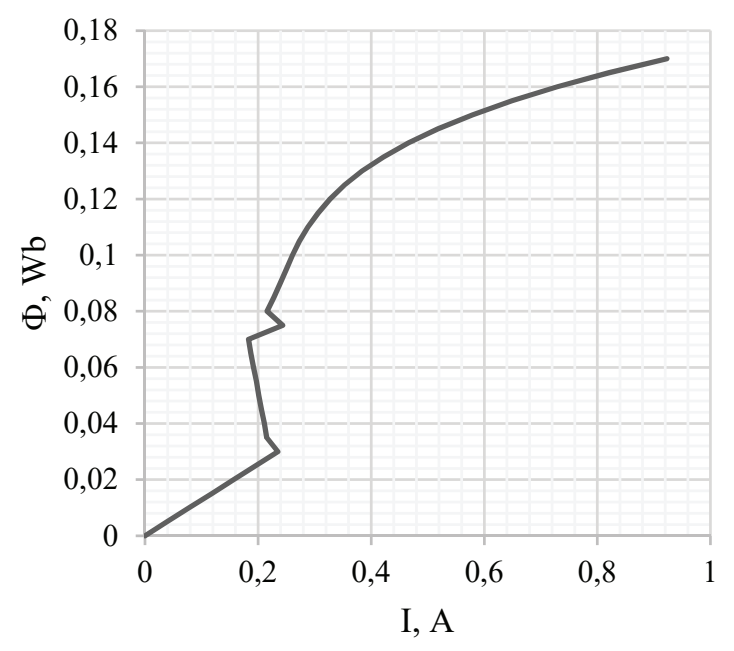

Fig. 3. DCM10 with a rough error introduced at one point $20 \%$

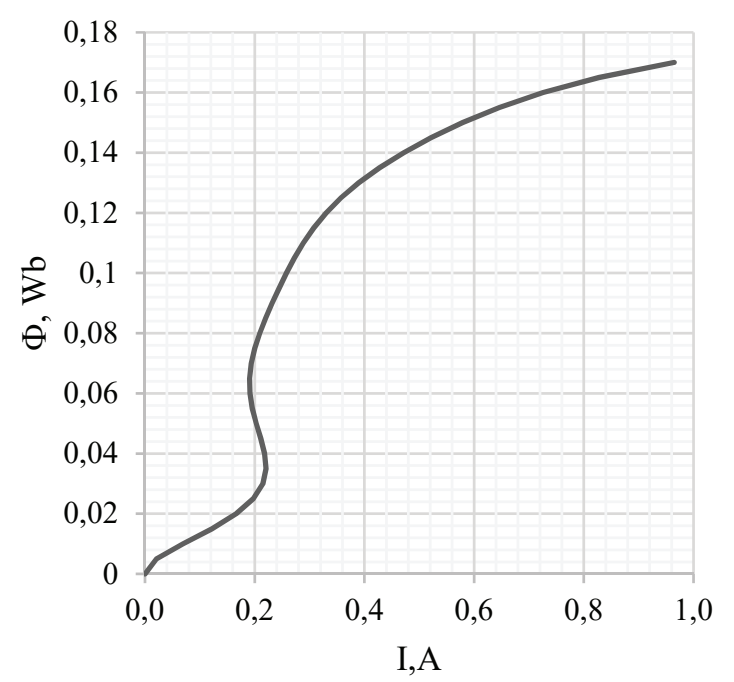

Fig. 4. Approximated DCM23 with an introduced error of $5 \%$

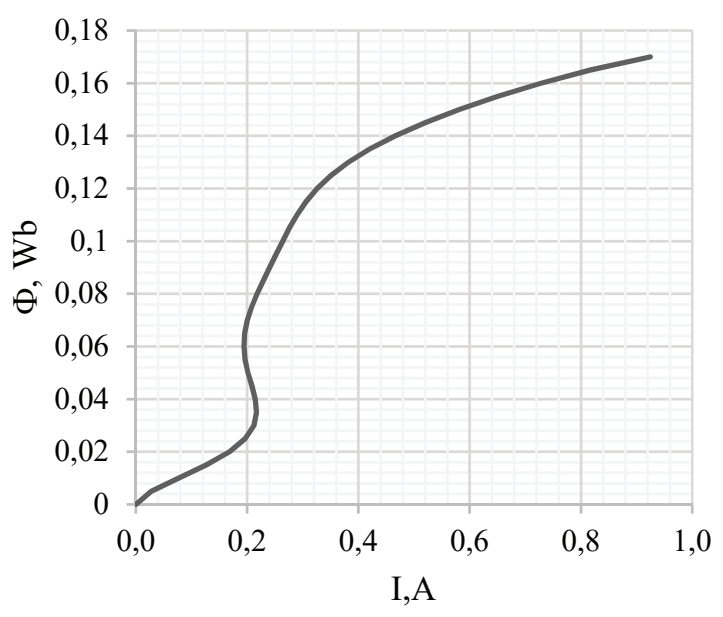

Fig. 5. Approximated DCM27 with a rough error introduced at one point $20 \%$

When the various DCM are combined, it is precisely the approximated curves that are closest to the original DCM.

Consider how the DCM will behave in the course of projecting into the space of the PC $[14,15,16]$. The purpose of the experiment in the analysis of the location of the points of the corresponding DCM2- DCM35 in the $\mathrm{PC}$ space with respect to the point of the corresponding DCM1.

First we consider the influence of a random error. In Figure 7, the grey dot depicts DCM1 without error and DCM2- DCM6 with extrinsic errors, and the greater the error, the further the DCM from the original one.

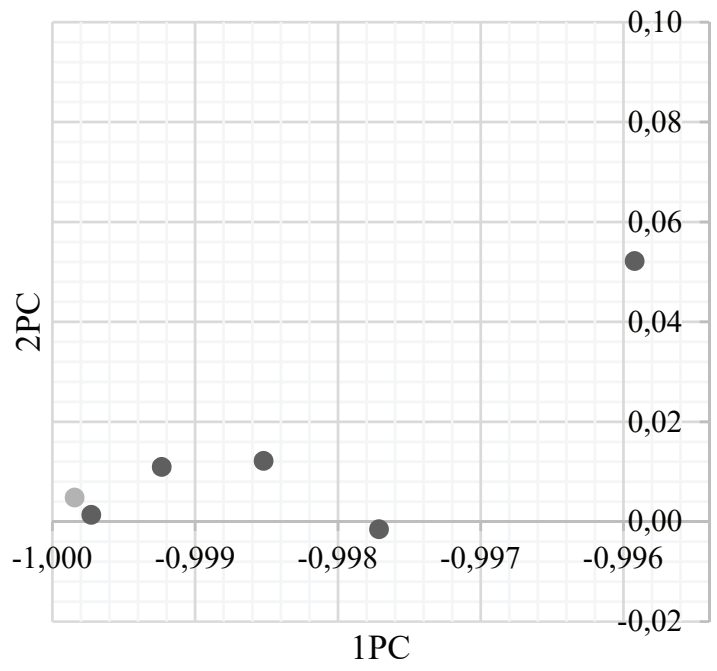

Fig. 7. Initial DCM1 and DCM2-DCM6 with errors from $1 \%$ to $5 \%$

After approximating DCM containing random errors (Figure 8), the points corresponding to them in the PC space become much closer to each other than the original DCM1 (the distance for DCM with a maximum random error of $5 \%$ was reduced by a factor of 12 ). 


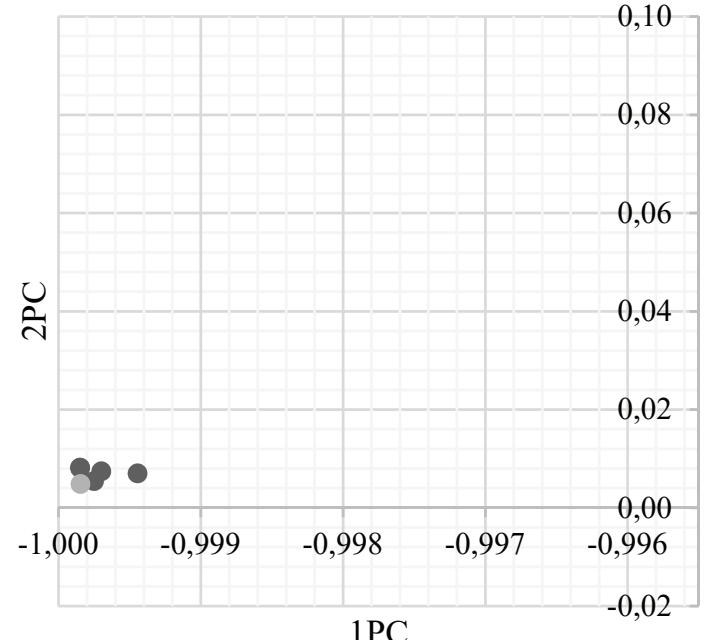

Fig. 8. Initial DCM1 and approximated DCM19-DCM23 with errors from $1 \%$ to $5 \%$

Next, consider the effect of gross errors. The initial DCM1 and DCM with a rough error at one point are shown in Fig. 9. There are significant effects of deviation from the initial DCM1 for gross errors of $15 \%$ and $20 \%$.

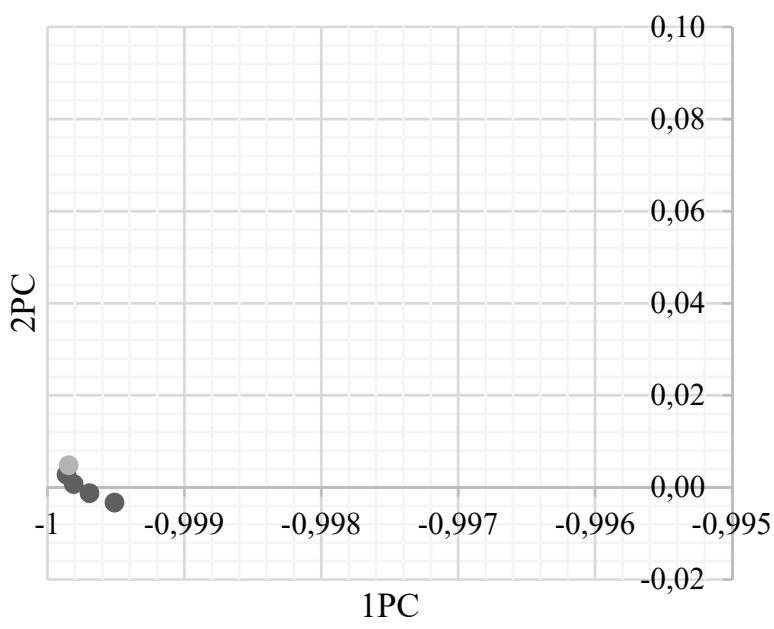

Fig. 9. Initial DCM1 and DCM7-DCM10 with a rough error at one point

After the approximation of the point in the space PC, as in the previous case, they become closer to each other (Figure 10).

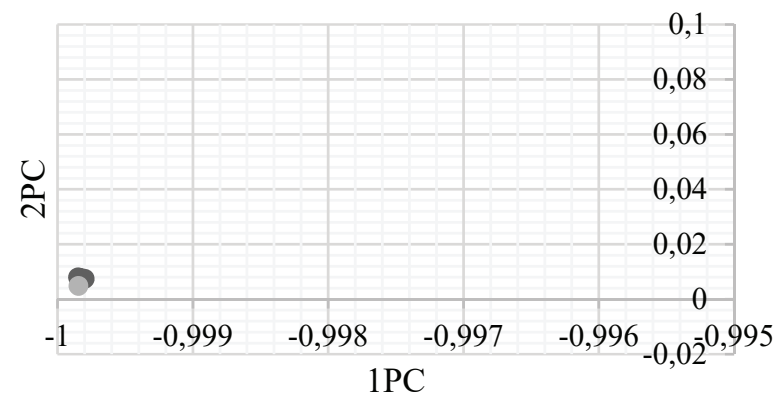

Fig. 10. Initial DCM1 and approximated DCM24DCM27 with a rough error at one point
The introduction of a rough error at three and five points affects the location of DCM in the PC space much more strongly, as can be seen in Figures 11 and 12 .

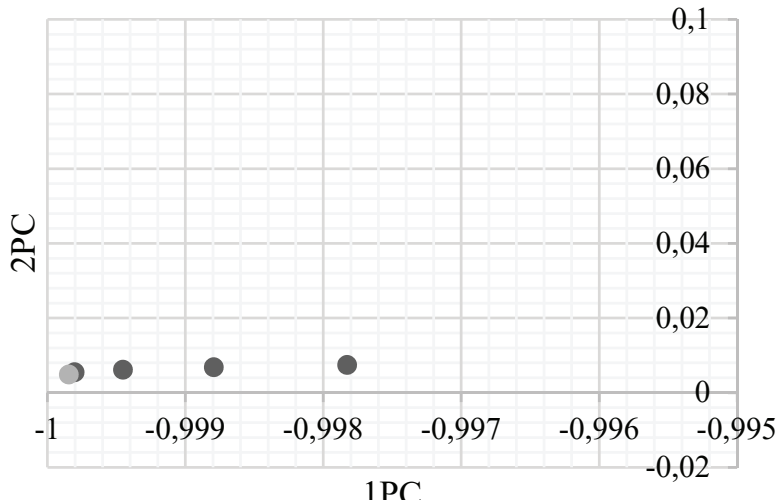

Fig. 11. Initial DCM1 and DCM11-DCM14 with a rough error at three points

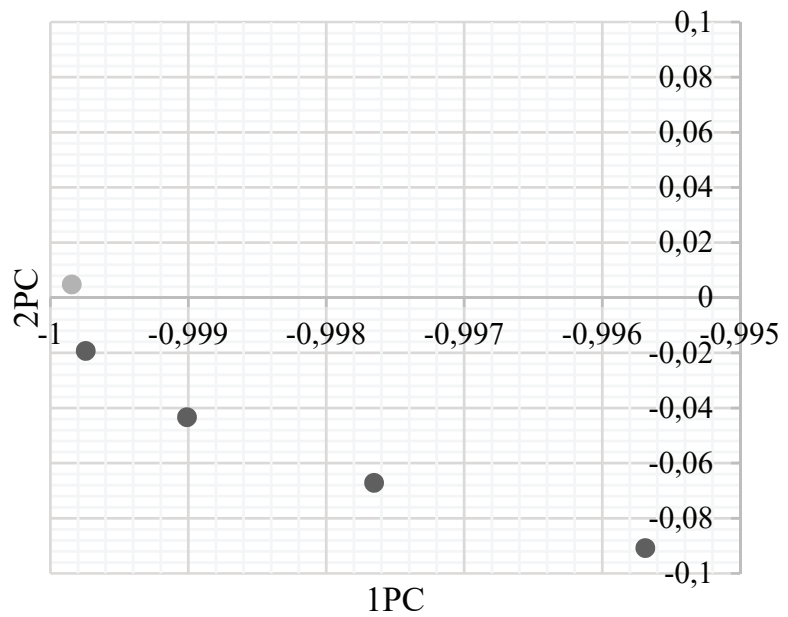

Fig. 12. Initial DCM1 and DCM15-DCM18 with a rough error at five points

After approximating DCM containing rough errors (Figs. 13 and 14), the points corresponding to them in the PC space become much closer to each other than the original DCM1 (the distance for DCM with a maximum gross error of $20 \%$ at five points was reduced by 25 times).

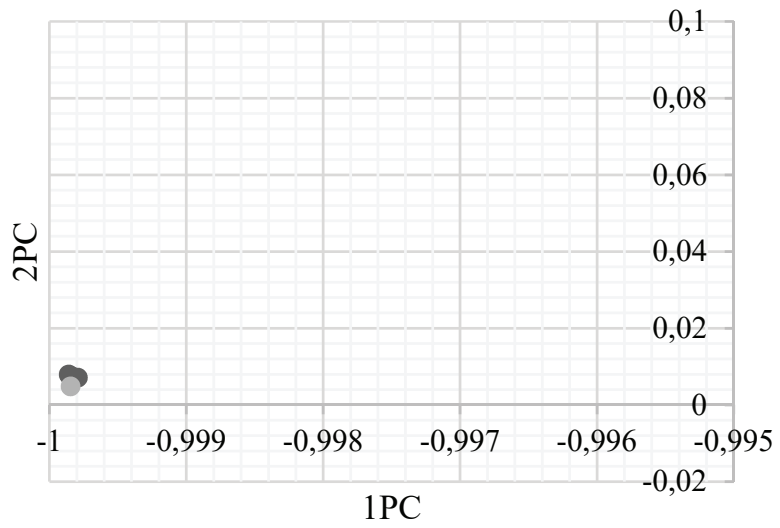

Fig. 13. Initial DCM1 and approximated DCM28DCM31 with a gross error at three points 


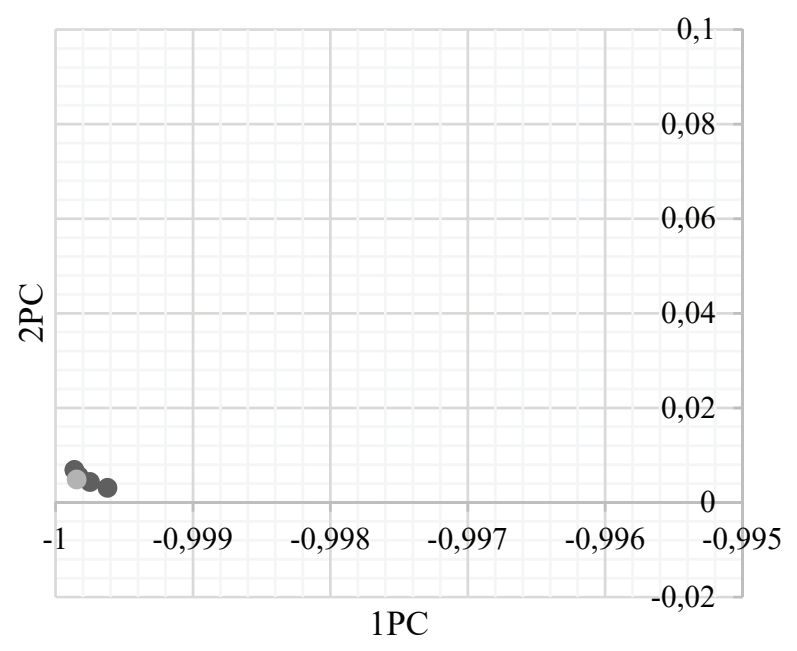

Fig. 14. Initial DCM1 and approximated DCM32DCM35 with a gross error at five points.

This confirms the operability of the proposed approach for solving the problem of increasing the stability of the PC method in the presence of random and gross errors (misses).

\section{Experimental studies of the influence of approximation}

The use of polynomial approximation raises the question of its effect on the sensitivity of DCM to the defects of proportional electromagnets. In connection with this, an experiment was carried out to project into the space of PC DCM of various proportional electromagnets before and after the approximation $[17,18,19]$.

For the comparison of DCM in the form of a series of points (magnetic flux, current) and polynomial approximation, DCM was selected for conditioning proportional electromagnets and a group of electromagnets with various defects (Table 3 ).

Table 3. Type of the DCM.

\begin{tabular}{|c|c|}
\hline $\begin{array}{c}\text { DCM } \\
\text { number }\end{array}$ & Defect type \\
\hline $36-38$ & No \\
\hline $39-41$ & Incomplete operation \\
\hline $42-44$ & Stuck anchor in triggered position \\
\hline
\end{tabular}

For the nine DCM, the first two PC, describing 95\% of the total variance (Table 4), are defined as a series of points and their corresponding characteristics in the form of a polynomial approximation.

Table 4 shows that there are minor deviations in the numerical values of DCM within $\pm 2.5 \%$ [20]. Let's construct the obtained values in the space of the first two PC (Figure 15).

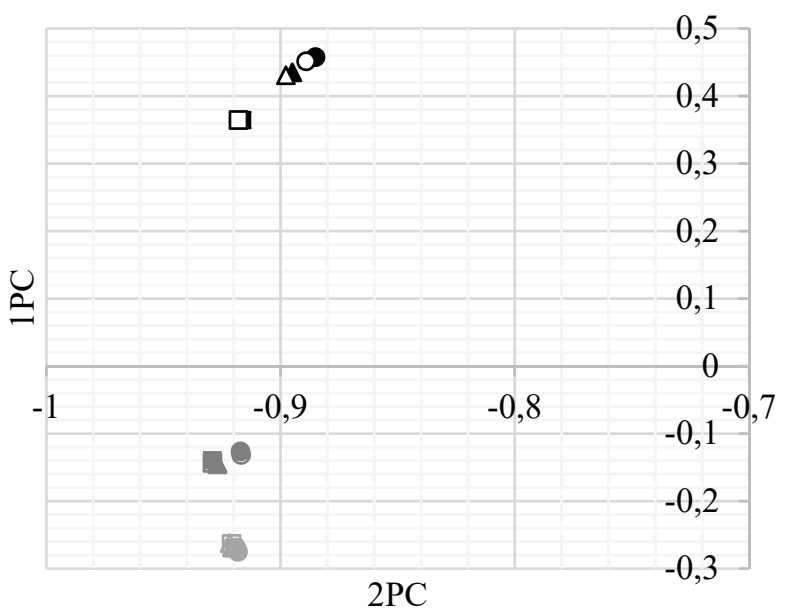

Fig. 15. Projections of DCM into the space of PC.

Table 4. The values of principal components.

\begin{tabular}{|c|c|c|c|c|}
\hline $\begin{array}{c}\text { Characteristic } \\
\text { type }\end{array}$ & \multicolumn{2}{|c|}{$\begin{array}{c}\text { DCM in the form } \\
\text { of a series of } \\
\text { points }\end{array}$} & \multicolumn{2}{|c|}{$\begin{array}{c}\text { Polynomial } \\
\text { approximation of } \\
\text { DCM }\end{array}$} \\
\cline { 3 - 6 } number & 1 ГК & 2 ГК & 1 ГК & 2 ГК \\
\hline ДХН 36 & $-0,916$ & 0,364 & $-0,918$ & 0,364 \\
\hline ДХН 37 & $-0,895$ & 0,435 & $-0,898$ & 0,431 \\
\hline ДХН 38 & $-0,885$ & 0,457 & $-0,889$ & 0,451 \\
\hline ДХН 39 & $-0,920$ & $-0,270$ & $-0,921$ & $-0,264$ \\
\hline ДХН 40 & $-0,921$ & $-0,269$ & $-0,922$ & $-0,262$ \\
\hline ДХН 41 & $-0,918$ & $-0,276$ & $-0,919$ & $-0,269$ \\
\hline ДХН 42 & $-0,929$ & $-0,140$ & $-0,929$ & $-0,144$ \\
\hline ДХН 43 & $-0,917$ & $-0,127$ & $-0,917$ & $-0,128$ \\
\hline ДХН 44 & $-0,927$ & $-0,144$ & $-0,927$ & $-0,146$ \\
\hline
\end{tabular}

\section{Conclusion}

Thus, the application of a proportional electromagnet to the DCM, the procedure for approximating a power polynomial of the sixth degree, makes it possible to increase the robustness of the diagnostic method and reduce the amount of measurement data without losing the sensitivity of DCM to the defects of proportional electromagnets.

The results of the work were supported by the project No. 2.7193.2017 / 8.9 "Development of the scientific basis for designing, identifying and diagnosing high-precision positioning systems using the inverse electrical engineering methodology" performed within the basic part of the state task.

\section{References}

1. A.M. Lankin, M.V. Lankin, M.Y. Lankina, IOP Conf. Ser.: MSE, 10, 012074 (2017)

2. N.I. Gorbatenko, M.V. Lankin, Elektrotekhnika 8, 55-58 (2004) 
3. A. Lankin, D. Shaykhutdinov, V. Grechikhin, D. Schuchkin, N. Narakidze, N. Gorbatenko, Jour. of Eng. and Appl. Sci., 12(2), 363-373 (2017)

4. B.T. Polyak, M.V. Khlebnikov, Automation and Telemechanics, 3, 130-148 (2017)

5. V.V. Grechikhin, M.V. Lankin, A.M Lankin, PromEng. WISTC, 235-238 (2015)

6. N.I. Gorbatenko, A.M. Lankin, M.V. Lankin, Procedia Engineering, 129, 799-803 (2015)

7. A.M. Lankin, M.V. Lankin, M.Y. Lankina, IOP Conf. Ser.: MSE, 10, 012075 (2017)

8. N.I. Gorbatenko, A.M. Lankin, M.V. Lankin, D.V. Shayhutdinov Inter. Jour. of Appl. Eng. Res., 10(3), 6509-6519 (2015)

9. A.M. Lankin, M.V. Lankin, N.I. Gorbatenko, D.V. Shayhutdinov MAS, 9(8), 247-261 (2015)

10. D.V. Shaikhutdinov, A.M. Lankin, N.D. Narakidze, V.V. Grechikhin, K.M. Shirokov, N.I. Gorbatenko Res. Jour. of Appl. Sci., 10(10), 555-557 (2015)

11. A.M. Lankin, M.V. Lankin, V.V. Grechikhin, D.V. Shaikhutdinov Res. Jour. of Appl. Sci., 10(10), 695-700 (2015)

12. N.I. Gorbatenko, A.M. Lankin, M.V. Lankin, Procedia Engineering, 150, 1027-1031 (2016)

13. A.M. Lankin, M.V. Lankin, O.A. Naugolnov, Procedia Engineering, 150, 1020-1026 (2016)

14. N.I. Gorbatenko, A.M. Lankin, M.V. Lankin, Met. Sci. and Heat Treat., 1-3 (2017)

15. N.I. Gorbatenko, A.M. Lankin, M.V. Lankin, Met. Sci. and Heat Treat., 4-6 (2017)

16. N.I. Gorbatenko, V.V. Grechikhin, M.V. Lankin, A.M. Lankin, Meas. Tech., 59(7), 747-751 (2016)

17. A.M. Lankin, M.V. Lankin, Nat. Ass. of Sch., 4-2 (9), 132-135 (2015)

18. A.M. Lankin, Mod. high tech., 9-3, 420-424 (2016)

19. A.M. Lankin, Bas. res., 9-3, 495-499 (2016)

20. M.V. Lankin, A.M. Lankin, IOP Conf. Ser.: MSE, 10, 012031 (2016) 